\title{
Implementation and Status of Biogas Technology in Ethiopia- Case of Tigray Region
}

\author{
Asfafaw H. Tesfay ${ }^{1,2 *}$, Mesele H. Hailu², Filmon A. Gebrerufael ${ }^{2}$ and \\ Muyiwa S. Adaramola ${ }^{3}$ \\ ${ }^{1}$ Institute of Energy Mekelle University, Mekelle, Ethiopia (*asfafaw.haileslassie@mu.edu.et). \\ ${ }^{2}$ School of Mechanical and Industrial Engineering, Ethiopian-institute of Technology-Mekelle, \\ Mekelle University, Mekelle, Ethiopia. \\ ${ }^{3}$ Faculty of Environmental Sciences and Natural Resource Management, Norwegian University of \\ Life Sciences (NMBU), Ås, Norway.
}

\begin{abstract}
In Ethiopia, like most developing countries, the majority of households depend on wood and charcoal as their cooking energy resources. This energy has a direct impact on the forest coverage and its emissions have significant health issues. Biogas technology has introduced to address these problems and reduce energy poverty in developing countries. However, the success of this technology depends on many factors such as technology appropriateness, available skill, proper introduction, and government support to create favorable financial incentives. The objective of this paper is to make an overview assessment of biogas development programs in Ethiopia, identify development barriers and provide suggestions to mitigate these barriers. The national and regional biogas program of Ethiopia has implemented to give energy for cooking and to some extent for lighting. However, it has shown limited success over the years. The National Biogas Programme of Ethiopia has shown an overall 50\% achievement while the Tigray region registered 55\% achievement. In addition, the owner of the biogas facility in Tigray reported a $57 \%$ functionality rate but the lowest satisfaction level of $15 \%$. Generally, the region has shown relatively better performance in terms of dissemination and functionality but a low satisfaction rate due to technical limitation, unsteady input, and financial factors.
\end{abstract}

Keywords: National Biogas Program, Biogas, Light cooking; Biogas lighting, Injera baking, Tigray, Ethiopia.

\section{INTRODUCTION}

Energy is a critical requirement for economic development and improved living conditions. Ethiopia, one of the least developed countries in the world with low Gross Domestic Product (GDP) and below average Human Development Index (HDI) has the lowest access to modern energy (Human Development Indices and Indicators, 2018). Its primary energy consumption is predominately derived from biomass and wastes (agriculture, urban and animal wastes), which accounts for $91 \%$ of the energy consumed, crude oil provides about $7 \%$ of total primary energy 
while hydropower, wind, diesel and coal accounts for only $2 \%$ of the total energy demand (Mondal et al., 2017; Berhanu et al., 2017).

The average annual energy consumption in Ethiopia is about $40000 \mathrm{GWh}$. The household sector accounts for about $93 \%$ of this energy (mainly for cooking and baking Injera), followed by transport sector (5\%), and industry and others accounted for 1\% (Mondal et al., 2017; Mengistu et al., 2015). Most of this energy comes from bioenergy resources, in which $\mathrm{CO}_{2}$ emissions increased from 5 million tons in 2005 to 6.5 million tons in 2010 and its per capita contribution from 0.06 ton in 2005 to 0.075 ton in 2010 (Mondal et al., 2017). Furthermore, indoor air pollution is causing more than 50,000 deaths annually and causes nearly $5 \%$ of the burden of disease from indoor cooking and poor ventilation (Abadi et al., 2017).

Ethiopia's rapid economic growth is creating steep increase in the energy demand across all sectors. While the rise in urban and manufacturing sector demand has attracted more attention, rural energy demand is also on the rise with rapid expansion in the use of biomass fuel sources resulting in environmental challenges related to air quality and deforestation. Biomass fuel is dominant energy supply in the household sector. It makes up $98.6 \%$ of the total energy consumption. Specifically, fuel wood, dung, crop residues, and charcoal account for $81.4 \%, 8.1 \%$, 7.8\%, and 1.3\%, respectively (Mohammed and Inoue, 2012; Mengistu et al., 2015).

There are numerous disadvantages of using woody biomass as fuel, which includes negative health effects due to accumulation of indoor smoke, deforestation and the timeconsuming and problems in wood fetching (Lemlem, 2016). To alleviate these problems, Ethiopia is pursuing sustainable and ecofriendly energy polices and strategies. Accordingly, investment and development of biogas technology have seen as one of such technology solutions.

This paper presents an overview status of biogas implementation in Tigray region, northern Ethiopia. Tigray is one of the nine regional states in Ethiopia, $6^{\text {th }}$ largest regional state by area. According to 2015 population projection, the region has an estimated population of 5.4 million that represents $6.1 \%$ of the country's population. The region also has a cattle population of more than 3,630,957 (World Fact book, 2017). The region has 80.5\% rural, and 19.5\% urban dwellers (Berhe et al., 2017). The region is comprised of seven zones, which in turn sub-divided into 34 rural woredas/districts.

One of the compelling reasons to promote biogas technology in Ethiopia is the livestock population particularly cattle, over 54,000,000 livestock, which is the largest in Africa and 
accounts for 3.68\% of global livestock population (World Cattle Inventory, 2015). In addition, the country uses massive chemical fertilizers to improve agricultural yield, however, biogas will have the potential to replace artificial fertilizer with bio slurries. Moreover, the country has enough locally available materials to develop domestic biogas technologies.

Table 1 shows the technical potential for domestic biogas in selected regions, based on the availability of livestock and access to water resources. These regions are the homes for roughly $70 \%$ of the livestock and over $70 \%$ of the population in the country (Gitonga, 1997). Eshete's study shows that biogas technology could benefit about 1.1 to 3.5 million households (Eshete et al., 2006).

Table 1. Technical potential for domestic biogas in Ethiopia (Eshete et al., 2006).

\begin{tabular}{|llllll|}
\hline Technical potential & Amhara & Tigray & SNNPR & Oromia & Total [households] \\
\hline Low Scenario & 255,361 & 75,591 & 159,340 & 641,033 & $1,131,325$ \\
\hline High scenario & 788,287 & 206,420 & 538,720 & 1978,840 & $3,512,267$ \\
\hline
\end{tabular}

In order to adopt biogas technology, each region has set up a criteria to meet the demand of the biogas beneficiaries. In Tigray, the potential beneficiary should fulfill the following conditions to be included in the biogas programme (Mekonnen and Paulos, 2008):

- Owning at least 4 cows/oxen

- Access to water supply

- Sufficient area for biogas plant installment

- Access to construction materials (sand, crushed and dry stone)

- Physical capability to excavate the pit for biogas plant, to muddle up the manure with water, to enter the manure and put out the slurry from the digester

In early periods, the biogas implementation in Ethiopia was not a centralized program. Biogas developments had initiated and implemented by the government, NGO's or both. Consequently, its distribution and implementation was random. This experience continued until 2009 when the country had developed its first national biogas program of Ethiopia (NBPE). It is a centralized biogas technology developments program in the country that was implemented in partnership with donors and developers. Looking at the impact of NBPE, the government continued the implementation of the second phase in 2012 and currently it is running its third phase, called NBPE+, which focuses on evaluation of NBPE1 and NBPE2. The review of this paper was made by categorizing the implementation as early stage and national biogas programs. 


\section{EARLY STAGE BIOGAS IMPLEMENTATION IN ETHIOPIA}

As per their chronological order, the early stage of biogas technology development and implementation in Ethiopia could be categorized into three generations.

\subsection{First Generation of Biogas Technology Implementation}

The first generation refers to the implementation of domestic biogas until 1965. The first biogas technology introduced in Ethiopia was in 1957 at Ambo Agriculture College to supply energy for welding of agricultural tools (Abadi et al., 2017; Kamp and Forn, 2016; Roopnarain and Adeleke, 2017). The installed system was batch digester unit, in which all the raw materials (water and waste materials) were added at the same time and kept for three to four weeks to decompose and subsequently the gas and bio-slurry were removed at the same time (Samer, 2012). The shortcoming of this technology is that it cannot continuously supply methane gas as it did not allow continuous feeding of slurry, this makes the technology inefficient and unacceptable. Nevertheless, government agencies in Ethiopia and the Food and Agriculture Organization (FAO) have made

efforts for couples of years to promote and accelerate this type of technology in the country (Smith et al., 2011). During 1970s, two biogas plants were introduced by FAO as pilot projects to further promote the technology in Ethiopia (Kamp and Forn, 2016). Though, SNV 2018 report (NBPE+, 2018) has indicated that two biogas digesters were installed at Ambo in 1962 but their size is unknown.

\subsection{Second Generation of Biogas Technology Implementation}

It refers to the implementation of biogas technology during 1980 to 2000. In this period, more than 1000 biogas plants were constructed, with a size range between 2.5 and $200 \mathrm{~m}^{3}$, by private and government agencies in different communities across the country (Abadi et al., 2017; Kamp and Forn, 2016; Roopnarain and Adeleke, 2017; NBPE+ 2018; Yilma, 2011). This implementation period focused at demonstrating the performance of different biogas technologies (Nigatu et al., 2012; Curry and Pillay, 2012). During this period, different models including fixed dome, Indian floating drum and bag digesters, were tested.

The cost-benefit analysis of fixed dome biogas model in Ethiopia indicates that its adoption has significant positive net present value for both households, who collect their own energy sources and for those that rely on purchasing their entire energy sources (Mohammed and Inoue, 2012; Gwavuya et al., 2012). However, approximately $60 \%$ of the installations were not operational (Abadi et al., 2017; Kamp et al., 2016; Roopnarain and Adeleke, 2017). In general, the fixed dome 
digester performed poorly and has little success in realizing market oriented, self-financing, and sustainable biogas programme. These shortcomings of the fixed dome digester lead to negative impact on the dissemination of biogas technology and discouraged potential users. However, this generation has opened a way to the third biogas technology program in the country.

\subsection{Third Generation of Biogas Technology Implementation}

This generation includes biogas developments that extended up to 2005. During the end of 1990s, Ethiopian and Germany governments have collaborated to update the biogas technology development in Ethiopia. Accordingly, 60 fixed-dome biogas digesters were built between 1999 and 2002 in Addis Ababa and Adama (NBPE+, 2018; Kellner, 2002; Yacob, 2017). The implementation in this generation also include the construction of the biogas digester locally and ensuring the promotion with successful installation and close surrounding. This triggered and motivated the local to construct additional biogas plants. In addition, SNV report has also shown that about 150 biogas digesters were constructed in Tigray in 2005 (NBPE+, 2018).

\section{NATIONAL BIOGAS PROGRAM ETHIOPIA (NBPE)}

Ethiopia has implemented nationally planned biogas program starting from 2009 (Smith et al., 2011). The NBPE has two phases, referred as Phase1 and Phase 2. NBPE1, 2009-2013, was implemented in four regions (Amhara, Oromia, SNNPR and Tigray). NBPE2 runs from 2014 to 2019 in the same regions. Dutch/DGIS and the Ethiopian Governments funded the NBPE1 and NBPE2. In NBPE+ phase (2017 to 2022), additional four regions (i.e. Somali, Benshangule Gumuz, Gambela and Afar regional states) have included in the programme. The funding for NBPE+ was obtained from European Union (EU) and the Ethiopian government.

The NBPE activities comprises of eight major components, which are promotion and marketing, training, quality management, research and development, monitoring and evaluation, institutional support, extension, and gender mainstreaming. The overall objective of the NBPEs is to facilitate the expansion of access to modern energy services through the introduction and development of biogas energy for rural households and communities. Hence, this programme is aimed to provide clean and safe energy for cooking and lighting in these communities. This approach could replace the use of wood and charcoal as well as chemical fertilizer to improve agriculture, health and livelihood conditions of the rural (Boers et al., 2008). Furthermore, it has aimed to develop commercially viable domestic biogas technology to ensure uninterrupted 
functions of biogas plants in the country. Specifically, the program was designed to (Eshete et al., 2006; Boers et al., 2008):

- Attract and strengthen institutions and organizations for the development of a national biogas sector

- Construct 14,000 biogas plants in selected regions over a period of 5 years

- Ensure continued operation of installed biogas plants under the NBPE

- Maximize the benefits of all biogas plants installed through private sector competition, it is expected that potential users would benefit from reduced costs and the business opportunities will grow through an increasing demand for biogas technology.

\subsection{National Biogas Program Ethiopia Phase one (NBPE1)}

The first phase of the NBPE, referred as five-year pilot implementation phase, was launched in 2009. The program has disseminated biogas plants in 18 selected districts (woredas) in Amhara, SNNP, Oromia, and Tigray regions as shown in table 2 (Abadi et al., 2017). The selection of these districts was based on the number of human and livestock population; the loss of vegetative cover; the districts' status with regard to educated human resources and technology adoption experience; the availability of relatively well-documented information; and woody biomass consumption that exceeds annual production in more than two-thirds of the districts (Berhe et al., 2017)

At the end of phase one implementation period, the program constructed 8063 biogas plants, which represent about $57.6 \%$ of initially planned 14000 installations in 163 sub-districts. The distribution of installed plants is 1892, 1699, 2001 and 2480 in Amhara (33 sub-districts), SNNP (23 sub-districts), Tigray (29 sub-districts) and Oromia (78 sub-districts) respectively (ABPP, 2017; TRBPCU, 2017), with various biogas digester sizes (4, 6, 8 and10 $\mathrm{m}^{3}$ ) and fixed dome model (Mengistu et al., 2016a and 2016b). Figure 1 shows the trends of yearly installed biogas plants in the four regions.

Table 2. Selected districts "woredas" to implement NBPE1 (Ghimire, 2008).

\begin{tabular}{|llll|}
\hline & & Region & \\
\hline Oromiya & Amhara & SNNP & Tigray \\
\hline Adaa & Bahir Dar Zuria & Dale & Hintalo Wajorat \\
\hline Dugda Bora & Dembia & Mareko & Raya Azebo \\
\hline Hetosa & Gonder Zuria & Meskan & Western Tigray \\
\hline Ambo & Fogera & Arba Minch zuria & \\
\hline Kuyu & Dangla & Derashe Special Woreda & \\
\hline
\end{tabular}




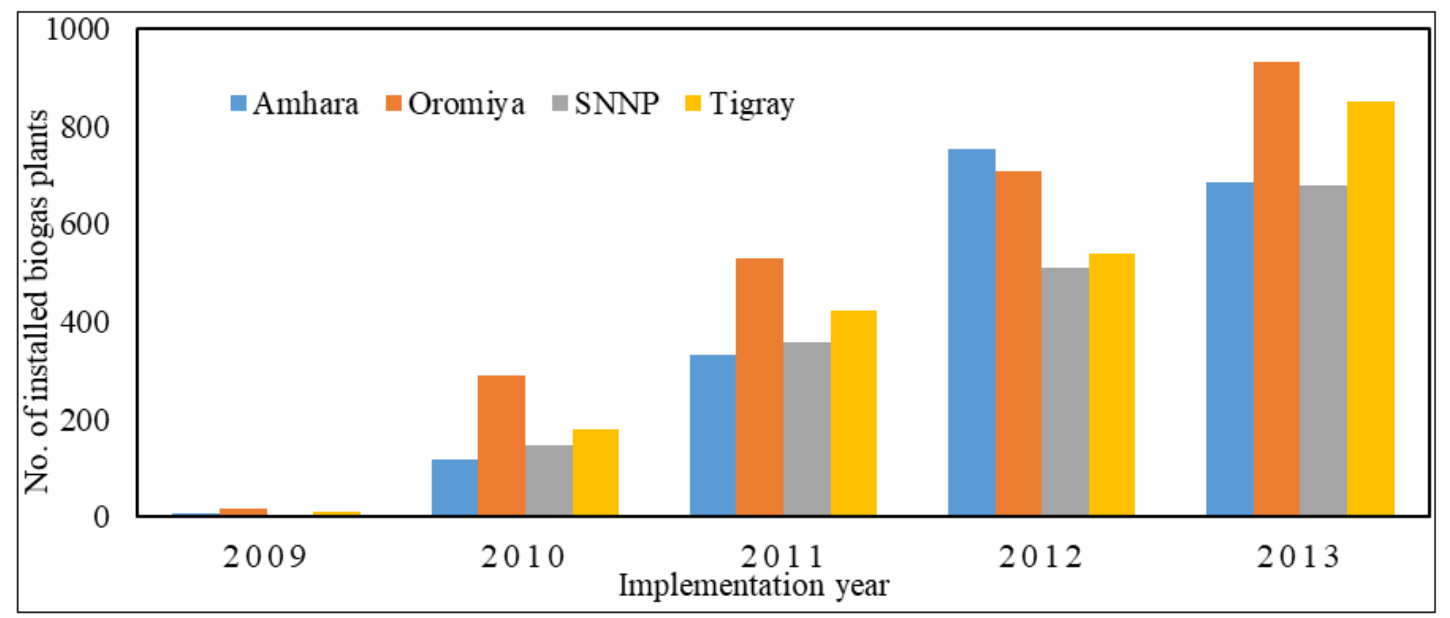

Figure 1. Biogas distribution in Ethiopia during NBPE1 implementation (Tsige, 2017).

The $42.4 \%$ failure to achieve the set target of NBPE1 is due to many factors (Tsige, 2017; Fkremariam, 2017; NBPE, 2008). That includes:

- Rising cost of construction material, which increase per digester cost.

- Insufficient or lack of skilled labor and expert

- Low commitment of stakeholders at regional level and lack of credit facilities in some regions because the beneficial are not well organized financially.

- Lack of continues follow up service after installation and commissioning.

- Limited application of the technology to lighting and light cooking

- Available alternative sources to satisfying their energy demand.

\subsection{National Biogas Program Ethiopia (NBPE2)-Phase two}

The second phase (2014-2019) known as scale up program, which targets at biogas dissemination by incorporating the lessons learned during the first phase. Specific objectives frames to be achieved during NBPE2 (Fkremariam, 2017) include:

- $\quad$ Scale up the dissemination of 20,000 biogas digesters

- $\quad$ Scale up the dissemination of biogas appliances for household cooking

- $\quad$ Pilot installation of larger size digesters

- $\quad$ Ensure long-term sustainability of biogas as a renewable energy

- $\quad$ Participation of alternative implementing partners and private micro-finance institutions 
During this phase, the program again focused mainly on the four regions selected in phase one. Table 3 shows the total number of biogas plants installed in the four regions from 2014 to 2016. In these three years, total biogas installations in the four regions was 7330 with an annual average of 2443 plants. It should be noted if this trend continues to 2019 . The achievement rate of NBPE2 is about $73 \%$ of the targeted number of installations. This would be an improvement on achievement rate of phase one.

Table 3. Installed biogas plants between 2014 and 2016.

\begin{tabular}{|llllll|}
\hline Year & Amhara & Oromiya & SNNP & Tigray & Total \\
\hline 2014 & 551 & 597 & 505 & 864 & 2517 \\
\hline 2015 & 601 & 364 & 513 & 782 & 2260 \\
\hline 2016 & 724 & 736 & 603 & 490 & 2553 \\
\hline
\end{tabular}

\subsection{Implementation of NBPE1 in Tigray}

In Tigray, the Tigray region biogas program coordinating office (TRBPCO) is under Tigray Mines and Energy Agency. TRBPCO is responsible for coordination, facilitation and monitoring of the cascaded NBP implementation. During this implementation phase, TRBPCO involved several stakeholders to speed up the dissemination process of the technology. Furthermore, TRBPCO get periodical advice, guidance and monitoring from the national biogas program coordination office and Tigray biogas steering committee (TRBPCU, 2017).

The first batch of biogas plants installation by NBP in the region was carried out in 2008 as demonstration phase of 15 biogas plants in Hintalo Wajirat with fixed dome digester model (Berhe et al., 2017; TRBPCU, 2017). Eventually, about 2001 biogas digesters have installed in 27 woredas out of the total 34 woredas in the region. The region experienced an increase annual biogas installation rate and functionality of $52 \%$ (Tsegu, 2017), as indicated in table 3 . It can be observed from table 3 that the $6 \mathrm{~m}^{3}$ digester size is the dominant technology with $97 \%$ of installation and $8 \mathrm{~m}^{3}$ and $10 \mathrm{~m}^{3}$ accounted for merely $0.9 \%$ and $1.9 \%$, respectively. The main reasons for this huge disparity in digester sizes is that the smallest size require low installation cost, relatively low cattle dung and it can also generate adequate methane gas for light cooking and lighting for one household (TRBPCU, 2017 and Tsegu, 2017).

During this phase, over $72 \%$ of the biogas plants were installed in four woredas, which fulfilled the selection criteria set by the program's office. These woredas are Hintalo Wajirat 
(39.2\%), Ofla (19.34\%), Kilte Awlaelo (6\%) and Enderta (8.34\%). On the other hand, because of lack of awareness on the technology by leaders in seven potential woredas, Tselemti, Gulomekeda, Tahtay Adiabo, Welkait, Tsegede, Tahtay Maichew and Kafta Hummera, no biogas plants were installed (NBPE+ Action Document for Ethiopia).

Table 3 presents a summary of yearly biogas digesters installation during 2009 to 2013 in Tigray region. The total installed biogas digester in phase one is 2001 with achievement rate of $57.17 \%$ but the intended target was 3500 (TRBPCU, 2017). It has also indicated that the $6 m^{3}$ digester size is the dominant technology with $97 \%$ of installation.

Table 3. Implemented digester size during phase one in Tigray (TRBPCU, 2017).

\begin{tabular}{|llcccccc|}
\hline Year & $\begin{array}{l}\text { Installed } \\
\text { biogas }\end{array}$ & $\mathbf{6 m}^{\mathbf{3}}$ & Percent (\%) & $\mathbf{8 m}^{\mathbf{3}}$ & Percent (\%) & $\mathbf{1 0 m}^{\mathbf{3}}$ & Percent (\%) \\
\hline 2009 & 10 & 10 & 100.0 & 0 & 0.0 & 0 & 0.0 \\
\hline 2010 & 179 & 173 & 96.6 & 1 & 0.6 & 5 & 2.8 \\
\hline 2011 & 422 & 389 & 92.2 & 9 & 2.1 & 24 & 5.7 \\
\hline 2012 & 538 & 530 & 98.5 & 4 & 0.7 & 4 & 0.7 \\
\hline 2013 & 852 & 842 & 98.8 & 5 & 0.6 & 5 & 0.6 \\
\hline
\end{tabular}

\subsection{Implementation of NBPE2 in Tigray}

TRBPCO, in this phase, has set to accomplish the following goals (TRBPCU, 2017; Tsegu, 2017):

- To increase dissemination of the technology by reducing the challenges faced during phase I;

- To implement and install digesters in all woredas of the region (34 woredas);

- To install additional 4622 digesters in the region; and

- To have uniform distribution of digester in all woredas.

Until the writing of this paper, the TRBPCO report shows that the installation of 2406 out of the 3777 initially target for the period of 2014 to 2017 have been achieved (see Table 5). The preferred digester sizes are $6 \mathrm{~m}^{3}, 8 \mathrm{~m}^{3}$ and $10 \mathrm{~m}^{3}$. The achievement rate increased from $77.3 \%$ in 2014 to $83.8 \%$ in 2015 and it drastically decreased to $42.6 \%$ and $47 \%$ in 2016 and 2017 respectively. The overall average achievement rate over the 42 months is $63 \%$, which shows slightly improvement when compared with phase I achievement rate of $57.17 \%$. According to TRBPCU (2017); Tsige (2017); Fkremariam (2017); Tsegu (2017), some of the reasons for this trend are shortage of water due to prolonged drought in 2015/2016, inability of the beneficiary to 
fulfill adequate cattle dung requirements, inability of digester system to supply energy required to bake Injera and low workmanship of the implemented plants.

Table 5. Targeted and actual installed biogas in phase II (TRBPCU, 2017; Tsige, 2017).

\begin{tabular}{|lrrrrr|}
\hline Year & $\mathbf{2 0 1 4}$ & $\mathbf{2 0 1 5}$ & $\mathbf{2 0 1 6}$ & $\mathbf{2 0 1 7}$ until July & Total \\
\hline Targeted biogas & 1115 & 933 & 1151 & 578 & 3777 \\
\hline Installed biogas & 862 & 782 & 490 & 272 & 2406 \\
\hline Installation achievement (\%) & 77.3 & 83.8 & 42.6 & 47.0 & 63.0 \\
\hline
\end{tabular}

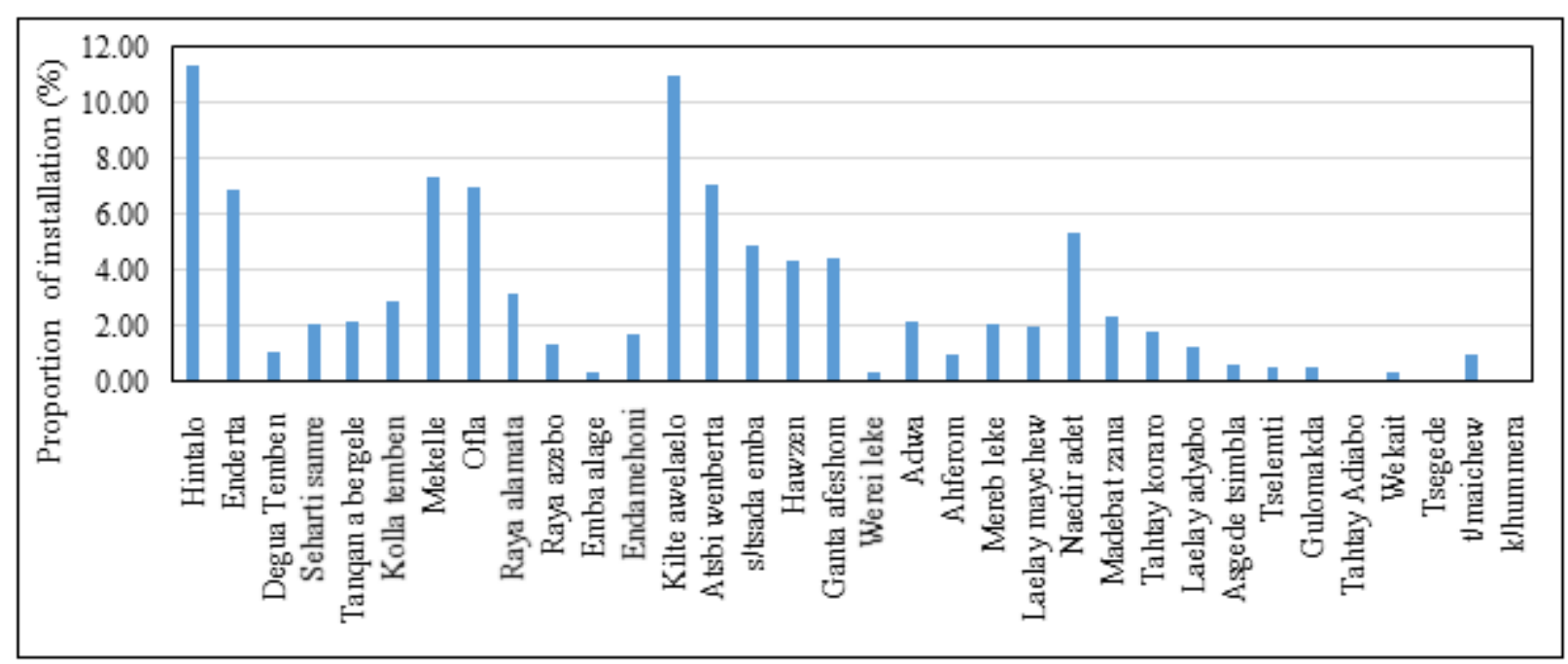

Figure 2. Biogas distribution in Tigray during phase II of the NBPE [(TRBPCU, 2017).

Table 6. Summary of digester size in Tigray during phase two (TRBPCU, 2017).

\begin{tabular}{|llcccccc|}
\hline Year & $\begin{array}{l}\text { Installed } \\
\text { biogas plants }\end{array}$ & $\mathbf{6 m}^{\mathbf{3}}$ & $\mathbf{( \% )}$ & $\mathbf{8 m ^ { 3 }}$ & $\mathbf{( \% )}$ & $\mathbf{1 0 m}^{\mathbf{3}}$ & $\mathbf{( \% )}$ \\
\hline 2014 & 862 & 861 & 99.9 & 1 & 0.1 & 0 & 0.0 \\
\hline 2015 & 782 & 776 & 99.2 & 0 & 0.0 & 6 & 0.8 \\
\hline 2016 & 490 & 490 & 100.0 & 0 & 0.0 & 0 & 0.0 \\
\hline 2017 & 272 & 270 & 99.3 & 0 & 0.0 & 2 & 0.7 \\
\hline
\end{tabular}

The TRBPCO shows good achivements in terms of set target implementation, however, $69.5 \%$ of the installations were in 10 woredas as shown in figure 2 that indicates uniformity of installation in all woredas is still challenging. Similar to phase one, the $6 \mathrm{~m}^{3}$ digester size is dominant with $99.6 \%$ installed distribution and $8 \mathrm{~m}^{3}$ and $10 \mathrm{~m}^{3}$ only accounted for $0.4 \%$ in this phase as shown in table 6 with similar reasons to phase I. 


\section{OVERALL BIOGAS INSTALLATIONS AND STATUS IN ETHIOPIA}

Many domestic biogas digesters have installed in Ethiopia since their introduction in 1957. During Phase I and II of the National Biogas Program, the number of digesters has increased significantly, especially in the four selected regions for implementation of NBPE. Table 7 shows the summary of biogas installations in Ethiopia between 2009 and 2016. The total installed digesters during this period is 15403 , which represent about $45.3 \%$ of the target (34 000) in the two NBPE phases.

Table 7. Biogas dissemination by NBP in phase I and II

\begin{tabular}{|llllllllll|}
\hline Region & $\mathbf{2 0 0 9}$ & $\mathbf{2 0 1 0}$ & $\mathbf{2 0 1 1}$ & $\mathbf{2 0 1 2}$ & $\mathbf{2 0 1 3}$ & $\mathbf{2 0 1 4}$ & $\mathbf{2 0 1 5}$ & $\mathbf{2 0 1 6}$ & Total \\
\hline Amhara & 7 & 117 & 331 & 752 & 685 & 551 & 601 & 724 & 3,768 \\
\hline Oromia & 16 & 291 & 531 & 709 & 933 & 597 & 364 & 736 & 4,177 \\
\hline SNNP & 4 & 147 & 358 & 510 & 680 & 505 & 513 & 603 & 3,320 \\
\hline Tigray & 10 & 179 & 423 & 538 & 852 & 864 & 782 & 490 & 4,138 \\
\hline Total & 37 & 734 & 1,643 & 2,509 & 3,150 & 2,517 & 2,260 & 2,553 & $\mathbf{1 5 , 4 0 3}$ \\
\hline
\end{tabular}

The applications of biogas technology in Ethiopia are mainly for light cooking and lighting at household, institute and commercial levels. Around $43 \%$ of the digester owners use biogas for both cooking and lighting, while $10.8 \%$ and $3.2 \%$ of them use it for only cooking and only lighting, respectively. On the other hand, $43 \%$ of the biogas adopters have not started using biogas due to incomplete installation and technical problems of the biogas plant (Berhe et al., 2017). Size wise, the cumulative biogas installation and distribution in Ethiopia has shown in Table 8. As compared to the four regions in phase I and II, there were very limited efforts in installing bio-digesters in the remaining regions of the country.

Table 8. Installation of biogas digesters in Ethiopia, until March 2017 (NBPE+, 2018).

\begin{tabular}{|l|l|l|l|l|l|l|l|l|l|}
\hline Region & Tigray & Amhara & Oromia & SNNPR & Somalia & $\begin{array}{l}\text { Benshangule } \\
\text { Gumuz }\end{array}$ & Gambela & Afar & Total \\
\hline $4 \mathrm{~m}^{3}$ & - & 112 & 97 & 17 & - & - & - & 1 & 227 \\
\hline $6 \mathrm{~m}^{3}$ & 4,146 & 1,933 & 2,059 & 2,542 & - & 10 & 7 & - & 10,697 \\
\hline $8 \mathrm{~m}^{3}$ & 20 & 1,771 & 1,400 & 747 & 15 & - & - & - & 3,953 \\
\hline $10 \mathrm{~m}^{3}$ & 44 & 122 & 577 & 118 & - & - & - & - & 861 \\
\hline Total & 4,210 & 3,938 & 4,133 & 3,424 & 15 & 10 & 7 & 1 & $\mathbf{1 5 , 7 3 8}$ \\
\hline
\end{tabular}

SNV's baseline study shows that the most widely installed biogas digester sizes were $6 \mathrm{~m}^{3}$ and $8 \mathrm{~m}^{3}$ with $68 \%$ and $25 \%$ national cumulative installations respectively. It can be seen that there were variations among the regions in terms of size distributions. Among the four common sizes (4 to $10 \mathrm{~m}^{3}$ ), biogas digester of size $4 \mathrm{~m}^{3}$ has been the least installed bio-digester in all regions. 
Similarly, $10 \mathrm{~m}^{3}$ size was not also common bio-digesters in all regions except Oromiya region has $67 \%$ of the total nation-wide installations in this size. In addition, the study shows that there were two common designs of bio-digesters that were installed in the country, namely the SINDU model and the SINDU 2008 model (NBPE+, 2018) as indicated in table 9. The SINIDU model was the first design that was promoted and installed in the country since the beginning of the Africa Biogas Partnership Program (ABPP). As a result, as of March 2017, almost 97\% of bio-digesters were SINIDU model while the remaining $3 \%$ were SINIDU 2008 models (NBPE+, 2018).

Table 9. Biogas digester distribution in terms of digester design model (NBPE+, 2018).

\begin{tabular}{|lllll|}
\hline Region & The SINDU Model & The SINDU2008 Model & Other models & Total \\
\hline Tigray & 4193 & 17 & & 4210 \\
\hline Amhara & 3563 & 373 & 3 & 3936 \\
\hline Oromia & 4055 & 75 & & 4133 \\
\hline SNNPR & 3423 & & 3423 \\
\hline Others & 33 & & 3 & 33 \\
\hline Total & 15,267 & 465 & $\mathbf{1 5 , 7 3 5}$ \\
\hline
\end{tabular}

The functionality rate of bio-digesters was found to be different for different regions. According to SNV baseline study, the functionality rate of biogas digesters in the country was about $54 \%$ as shown in table 10 (NBPE+, 2018). While, functionality of digesters in regions report is not consistent.

Table 10. Biogas digester functionality percentage of regions (NBPE+, 2018 \& NBPE).

\begin{tabular}{|lccc|}
\hline Region & BUS Report, 2015 & PAV Report, 2015/16 & SNV Report, 2018 \\
\hline Tigray & $66 \%$ & $51 \%$ & $57 \%$ \\
\hline Amhara & $88 \%$ & $90 \%$ & $50 \%$ \\
\hline Oromia & $72 \%$ & - & $57 \%$ \\
\hline SNNPR & $78 \%$ & $48 \%$ & $50 \%$ \\
\hline
\end{tabular}

There are different reasons for the non-functionality of biogas digesters, however, slurry feeding and technical problems found the major roadblocks as shown in table 11. The feeding problems arise from irregularity of feeding, over feeding and not enough initial feeding. The Technical problem are also leveled as construction related problems including technical defects of the digester such as incomplete foundation, drainage problem, pipe leakage, dome crack and others. Other causes of non-functionality include (NBPE+, 2018):

- Lack of accessories/spare appliances 
- Water supply problem

- Relocation of users or due to death of the owners

- Owner's cattle sold, and

- Promotional problems

Table 11. Causes for non-functionality and their share of different regions (TRBPCU, 2017).

\begin{tabular}{|llllll|}
\hline Region & \multicolumn{5}{c|}{ Causes for non-functionality and their share (in \%) } \\
\cline { 2 - 6 } & $\begin{array}{l}\text { Feeding } \\
\text { problem }\end{array}$ & $\begin{array}{l}\text { Technical } \\
\text { problem }\end{array}$ & $\begin{array}{l}\text { Water } \\
\text { supply }\end{array}$ & $\begin{array}{l}\text { Spare part accessories } \\
\text { /appliances }\end{array}$ & others \\
\hline Tigray & $40 \%$ & $36 \%$ & $4 \%$ & $12 \%$ & $8 \%$ \\
\hline Amhara & $24 \%$ & $53 \%$ & - & $13 \%$ & $10 \%$ \\
\hline Oromia & $25 \%$ & $47 \%$ & $10 \%$ & $9 \%$ & $9 \%$ \\
\hline SNNPR & $41 \%$ & $43 \%$ & - & - & $16 \%$ \\
\hline
\end{tabular}

Based on experience acquired during the NBPE I and II, the following issues need to be addressed (NBPE+ Action Document for Ethiopia):

- High up-front initial capital investment for the farmers require some level of subsidy

- Household access to credit facilities is still limited and needs to be expanded and improved, with a particular attention given to women and female headed households

- Increased and stronger implementing promotion, technical support and use of bio-slurry

- Considering the first steps of familiarizing Ethiopia with biogas and engaging local stakeholders in this sector, there is a need to increase the number and types of implementing partners, introduction of result-based financing implementation modalities and increased focus on private sector, or Micro and Small Enterprise (MSE),

- Beyond installation, there is a need to maintain bio-digesters quality to assure its use and develop trust on the technology.

Finally, strong commitment is required from individual, both federal and regional government agencies, private organizations as well as NGOs to adopt biogas system as viable component of the overall energy systems in Ethiopia. Improving current skilled labor, in design and construction of biogas plants as well as their maintenance, with contribution from various stakeholders would significantly contribute to increase its adoption. 
Ethiopia has conducted a national biogas user survey in ten Zones and seventeen Woredas in the four implementing regions and the survey shows the NBPE has achieved about $50 \%$ of its plan. The survey shows Amhara region has achieved about $67 \%$ of its target, Oromia 43\%, SNNPR $59 \%$ and Tigray $55 \%$ of their targets. It also shows about $89 \%$ of the biogas users have installed $6 \mathrm{M}^{3}$ biogas digester (NBPE, 2008; Report on National Biogas Users' Survey, 2018). In addition, the survey shows a national functionality rate of $77 \%$ and $65 \%$ in Tigray region. Moreover, it indicated that biogas has significant contributions in improving many aspects of the users' lives and the community in general. Some of the contributions are in terms of forest coverage, health situation with regard to cough, respiratory and eye problems, children's studying time, reduced violence against women and girls and improved women's participation in social and productive economic activities. Furthermore, biogas users are also applying the slurry in their farmyards that helped them to increase their productivity. However, the application of slurry did not significantly reduce the use of chemical fertilizers. On the other hand, the dissemination of biogas technologies requires more promotion, after sales service and new technology for intensive cooking such as Injera baking. The survey has also shown, Tigray region has $56 \%$ alternative energy supply options to biogas and show a $15 \%$ satisfaction level on the technology.

\section{CONCLUSION}

Biogas implementation in Ethiopia generally shows low performance due to technical and nontechnical challenges. The primary target of the national biogas programs is to introduce biogas technology for light cooking and lighting, that has missed to address important cooking activity mainly Injera backing and intensive cooking in general. In addition to limited digester capacity, poor workmanship and related performance problems has limited the success of biogas. Moreover, similar to technical challenges the non-technical factors especially promotion has played a limited role in creating awareness about the versatility of the technology. In some part of Tigray region, the cost of wood fuel is higher than food items and the implementation of biogas was expected to demonstrate a good intervention solution. However, the low satisfaction level in the region has indicated that biogas programs need to upgrade their technical versatility to supply energy for baking, adequate energy for lighting, transportation etc. Furthermore, biogas promotion has to focus on energy poverty reduction, advantage of bio slurry over chemical fertilizer and its subsidy scheme in order to bring a successful implementation. 


\section{ACKNOWLEDGEMENTS}

The authors are thankful to the unlimited support and collaboration of Tigray region energy bureau to access data and unpublished information regarding biogas implementation in Ethiopia and Tigray in particular.

\section{CONFLICT OF INTERESTS}

No conflict of interests.

\section{REFERENCE}

ABPP (Africa biogas partnership program). 2017. http://www.africabiogas.org/countries/ethiopia Abadi, N., Gebrehiwot, K., Techane, A \& Nerea, H. 2017. Links between biogas technology adoption and health status of households in rural Tigray, Northern Ethiopia. Energy Policy, 101: 284-92.

Berhanu, M., Jabasingh, S.A \& Kifile, Z. 2017. Expanding sustenance in Ethiopia based on renewable energy resources-A comprehensive review. Renewable and Sustainable Energy Reviews, 75: 1035-1045.

Berhe, T.G., Tesfahuney, R.G., Desta, G.A \& Mekonnen, L.S. 2017. Biogas Plant Distribution for Rural Household Sustainable Energy Supply in Africa. Energy and Policy Research, 4(1): 10-20.

Boers, W., Workneh, K \& Esthete, G. 2008. National Biogas Programme Ethiopia Programme Implementation Document. Ethiopia Rural Energy Development and Promotion Centre, Addis Ababa, Ethiopia. 2008.

Curry, N \& Pillay, P. 2012. Biogas prediction and design of a food waste to energy system for the urban environment. Renewable Energy, 41: 200-209.

Eshete, G., Sonder, K \& Ter Heegde F. 2006. Report on the feasibility study of a national programme for domestic biogas in Ethiopia. SNV Netherlands Development Organization, Addis Ababa, Ethiopia.

FDRE (Federal Democratic Republic Of Ethiopia). 2018. Ministry Of Water, Irrigation and Electricity National Biogas Program Of Ethiopia. Report on National Biogas Users' Survey.

Fkremariam, T. 2017. Personal communication: Data base expert and member of program implementer in Tigray Region Biogas Program Coordination Office (TRBPPO). 
Ghimire, P. 2008. Training of trainers (TOT) on construction and supervision of SINIDU model biogas plant for Ethiopia: trainee's manual prepared for national biogas programme. Addis Ababa: Ethiopian Rural Energy Development and Promotion Center (EREDPC) and the Netherlands Development Organization in Ethiopia (SNV_Ethiopia).

Gitonga, S.1997. Biogas Promotion in Kenya: A review of experiences. Practical ActionTechnology Challenging Poverty, 25p (www.practicalaction.org).

Gwavuya, S., Abele, S., Barfuss, I., Zeller, M \& Müller, J. 2012. Household energy economics in rural Ethiopia: A cost-benefit analysis of biogas energy. Renewable Energy, 48: 202-209.

Human Development Indices and Indicators: 2018 Statistical Update, Briefing note for countries on the 2018 Statistical Update.

Kamp, L.M \& Forn, E.B. 2016. Ethiopia' s emerging domestic biogas sector: Current status, bottlenecks and drivers. Renewable and Sustainable Energy Reviews, 60: 475-88.

Kellner, C. 2002. Manual for the construction of a bio digester, "LUPO" design. Addis Ababa, Ethiopia: Deutscher Entwicklungsdienst (DED).

Lemlem, T. 2016. Bio-Gas Technology Adoption in Rural Ethiopia: It's Effect on the Crisis of Deforestation. Journal of Energy Technologies and Policy, 6(1): 1-8.

Mekonnen and Paulos, 2008. National Biogas Programme Ethiopia: Operational, Financial and Administrative Manual.

Mengistu, M., Simane, B., Eshete, G \& Workneh, T. 2015. A review on biogas technology and its contributions to sustainable rural livelihood in Ethiopia. Renewable and Sustainable Energy Reviews, 48: 306-316.

Mengistu, M.G., Simane, B., Eshete, G \& Workneh, T.S. 2016a. Factors affecting households' decisions in biogas technology adoption, the case of Ofla and Mecha Districts, northern Ethiopia. Renewable Energy, 93: 215-227.

Mengistu, M.G., Simane, B., Eshete, G \& Workneh, T.S. 2016b. The environmental benefits of domestic biogas technology in rural Ethiopia. Biomass and Bioenergy, 90:131-138.

Mohammed, A.J \& Inoue, M. 2012. The third national report on the implementation of the UNCCD/NAP in Ethiopia The third national report on the implementation of the UNCCD/NAP in Ethiopia, 2004. Journal of forest research, 17: 30-36. 
Mondal, M.A.H., Bryan, E., Ringler, C \& Rosegrant, M. 2017. Ethiopian power sector development: Renewable based universal electricity access and export strategies. Renewable and Sustainable Energy Reviews, 75: 11-20.

NBPE (National Biogas Programme of Ethiopia). 2008. Programme Implementation Document. Ethiopia Rural Energy Development and Promotion Centre (EREDPC).

NBPE (National Biogas Programme of Ethiopia). 2015. Report on Biogas Users' Survey (BUS).

NBPE+(National Biogas Programme of Ethiopia). 2018. Biogas Dissemination Scale-Up Programme.

NBPE+. 2018. Biogas Dissemination Scale-Up Programme. Programme baseline study report.

Nigatu, A.S., Karlsson, A \& Mandere, N.M. 2012. A comparative and evaluative study of potential biogas production from crops of teff (Eragrostis tef (Zucc) Trotter) in Ethiopia. African Journal of Biotechnology. 11: 8103-8109.

Roopnarain, A \& Adeleke, R. 2017. Current status, hurdles and future prospects of biogas digestion technology in Africa. Renewable and Sustainable Energy Rev., 67:1162-1179.

Samer, M. 2012. Biogas plant constructions. Biogas: InTech.

Smith, J., Austin, G., Avery, L \& Balana, B. 2011. The potential of small-scale biogas digesters to alleviate poverty and improve long term sustainability of ecosystem services in SubSaharan Africa. Institute of Biological and Environmental Science, Univ. of Aberdeen.

TRBPCU (Tigray Region Biogas programme Coordination Unit). 2017. List of Domestic Biogas Plants ( 2013 - 2017), Tigray Region Mine and Energy Agency.

Tsegu, K. 2017. Personal communication: Manager of Tigray Region Biogas Program Coordination Office (TRBPPO).

Tsige, G. 2017. Personal communication: Member of program implementer in Tigray Region Biogas Program Coordination Office.

World Cattle Inventory: Ranking of countries (FAO). Rob Cook, August 02, 2015.

World Fact Book, 2017. Ethiopia people 2017. CIA world fact book. http://www.theodora.com/wfbcurrent/ethiopia/ethiopiapeople.html source: 2017.

Yacob, Z. 2017. Personal communication: Regional Technical deputy Advisor at BORDA.

Yilma, D. 2011. The status of biogas technology in Ethiopia. A paper presented in workshop on the potential of small-scale biogas digesters in Sub-Saharan Africa Addis Ababa University, pp. 8-16. 